OPINI

\title{
KEBIJAKAN PENGEMBANGAN ARSIPARIS DI INDONESIA \\ DAN TANTANGANNYA DALAM MENGHADAPI \\ MASYARAKAT EKONOMI ASEAN (MEA)
}

\author{
Kurniatun
}

\begin{abstract}
Abstrak
Dengan berlakunya Masyarakat Ekonomi Asean (MEA) 2015 tuntutan terhadap arsiparis pun ikut meningkat. Arsiparis Indonesia harus mampu bersaing dengan sumber daya kearsipan dari sesama negara Asean agar dapat menjadi tuan rumah di negara sendiri. Salah satu cara pembuktian bahwa arsiparis mempunyai kompetensi dalam bidang kearsipan adalah dengan sertifikasi arsiparis.
\end{abstract}

Kata kunci: arsiparis, sertifikasi.

\section{A. Pendahuluan}

Pada tahun 2015 sudah sering kita dengar atau baca istilah MEA baik di media elektronik maupun media cetak serta tuntutan kesiapan untuk menghadapinya. MEA 2015 merupakan realisasi pasar bebas di kawasan Asia Tenggara yang sudah dicanangkan pada Konferensi Tingkat Tinggi (KTT) Asean di Singapura pada tahun 1992. Adapun tujuan dibentuknya MEA adalah untuk meningkatkan stabilitas perekonomian di kawasan Asean dan diharapkan dapat mengatasi permasalahanpermasalahan di bidang ekonomi antar negara anggota Asean. Dampak dari kesepakatan MEA tersebut adalah adanya aliran bebas barang dari dan ke negaranegara anggota Asean, arus bebas jasa, arus bebas investasi, arus bebas tenaga kerja, dan arus bebas modal. Hal itu dapat berdampak positif dan negatif bagi Indonesia. Dampak positifnya bagi 
Indonesia adalah Indonesia dapat memperluas jangkauan investasi dan pemasaran produk-produk di kawasan Asia Tenggara dengan biaya yang lebih murah. Tenaga kerja Indonesia juga bisa bebas bekerja di kawasan Asean. Dampak negatifnya yaitu mutu pendidikan tenaga kerja yang masih rendah akan menjadi peluang bagi negara-negara Asean lainnya untuk mengisi sektor pasar tenaga kerja di Indonesia.

Oleh karena MEA sudah mulai berlaku, pemerintah Indonesia diharapkan dapat mempersiapkan dan melakukan langkah strategis dalam sektor pasar tenaga kerja ini dalam rangka memberikan perlindungan kepada warga negaranya agar dapat menjadi tuan rumah di negeri sendiri, termasuk dalam bidang kearsipan. Persaingan MEA yang ketat menuntut Indonesia untuk mempersiapkan arsiparis agar mampu bekerja dengan terampil, cerdas, dan kompetitif. Sebagai Lembaga Pembina Kearsipan Pusat, Arsip
Nasional Republik Indonesia sudah melakukan beberapa kebijakan dalam menghadapi MEA.

\section{B. Rumusan Masalah}

Berdasarkan uraian dapat dirumuskan permasalahan "Bagaimana kebijakan dan langkah-langkah strategis yang dilakukan oleh ANRI dalam mempersiapkan sektor kearsipan khususnya arsiparis dalam menghadapi MEA?"

\section{Kerangka Pemikiran}

Dalam kerangka teori ini disampaikan pengertian MEA dan beberapa istilah yang terkait dengan sertifikasi arsiparis. MEA merupakan kependekan dari Masyarakat Ekonomi Asean yang dalam bahasa Inggris-nya Asean Economic Community (AEC) adalah sebuah integrasi ekonomi Asean dalam menghadapi perdagangan bebas antar negara-negara Asean. Sepuluh negara anggota Asean (Filipina, Indonesia, Malaysia, Singapura, Thailand, Brunei 
Darussalam, Vietnam, Laos, Myanmar, Kamboja) telah menyepakati perjanjian ini. MEA dirancang untuk mewujudkan Wawasan A sean 2020 (https://id.wikipedia.org/wiki/ Masyarakat_Ekonomi_Asean).

Berikut adalah beberapa pengertian terkait dengan sertifikasi arsiparis:

1. Arsiparis adalah seseorang yang memiliki kompetensi di bidang kearsipan yang diperoleh melalui pendidikan formal dan/atau pendidikan dan pelatihan kearsipan serta mempunyai fungsi, tugas, dan tanggung jawab melaksanakan kegiatan kearsipan. (UU No. 43 Tahun 2009 tentang Kearsipan, pasal $1(10)$.

2. Sertifikasi adalah pernyataan kesesuaian dari pihak ke tiga terkait dengan produk, proses, sistem manajemen atau personal terhadap standar tertentu (http://www.kan. or.id/?page_id=70\&lang=id)

3. Sertifikasi adalah rangkaian kegiatan untuk memberikan pengakuan formal kepada sumber daya manusia kearsipan oleh ANRI sebagai pengakuan terhadap kompetensi dalam bidang kearsipan (PP No 28 tentang Pelaksanaan UU No. 43 Tahun 2009 tentang Kearsipan).

4. Kompetensi merupakan seperangkat pengetahuan, keterampilan, dan perilaku yang harus dimiliki, dihayati, dikuasai, dan diaktualisasikan o $1 \mathrm{e} \mathrm{h} \mathrm{g} \mathrm{u} \mathrm{r} \mathrm{u} \mathrm{d} 1 \mathrm{a} \mathrm{m}$ melaksanakan tugas k e profe s i o n a 1 a n (http://kompetensi.info/komp e ten s i - guru / a p a - it u kompetensi.html)

5. Kompetensi adalah $\mathrm{ke}$ e a pu a $\quad \mathrm{d}$ a $n$ karakteristik yang dimiliki oleh seseorang berupa pengetahuan, keahlian dan sikap atau perilaku yang diperlukan dala m pelaksanaan tugas jabatannya (Perka ANRI no. 6 Tahun 2016).

6. Sertifikasi Jabatan 
Fungsional Arsiparis adalah proses pemberian sertifikat kompetensi kearsipan kepada Arsiparis PNS yang dilakukan secara sistematis dan obyektif melalui uji kompetensi yang mengacu pada Standar Kompetensi Jabatan Fungsional Arsiparis (Perka ANRI no. 6 Tahun 2016).

7. Sertifikat Kompetensi Kearsipan adalah bukti tertulis yang diterbitkan oleh ANRI sebagai bentuk pengakuan formal yang menerangkan bahwa seseorang telah lulus uji kompetensi baik aspek pengetahuan, keterampilan maupun sikap kerja (perilaku) sehingga yang bersangkutan diakui kompeten dan dipercaya dapat melaksanakan pekerjaan kearsipan (Perka ANRINo. 6 Tahun 2016).

8. Standar Kompetensi Jabatan Fungsional Arsiparis yang selanjutnya disingkat menjadi Stand ar
Kompetensi Arsiparis adalah rumusan kemampuan kerja di bidang kearsipan yang $\mathrm{me} \mathrm{n} \mathrm{c} \mathrm{a} \mathrm{k} \mathrm{u} \mathrm{p} \mathrm{a} \mathrm{s} \mathrm{p} \mathrm{e} \mathrm{k}$ pengetahuan, keterampilan dan/atau keahlian, sikap kerja yang minimal harus dimiliki Arsiparis dengan melaksanakan tugas sesuai kualifikasi kompetensi yang telah ditetapkan sesuai dengan ketentuan peraturan perundang-undangan yang berlaku (Perka ANRI no. 6 Tahun 2016).

Produk hukum yang telah ditetapkan di Indonesia dalam rangka mempersiapkan SDM Indonesia menuju MEA, yang termasuk di dalamnya arsiparis adalah sebagai berikut:

1. UU No.13 tahun 2003 tentang Ketenagakerjaan;

2. UU No 43 Tahun 2009 tentang Kearsipan;

3. PP No. 23 tahun 2004 tentang Badan Nasional Sertifikasi Profesi (BNSP);

4. PP No. 31 tahun 2006 tentang Sistem Pelatihan Kerja 
Nasional (Sislatkernas);

5. PP No. 28 Tahun 2012 tentang Pelaksanaan UU No 43 Tahun 2009 tentang Kearsipan;

6. Perpres No. 8 tahun 2012 tentang Kerangka Kualifikasi Nasional Indonesia (KKNI);

7. Permenaker No. 21 tahun 2014 tentang Pedoman Penerapan Kerangka Kualifikasi Nasional Indonesia;

8. Peraturan Menteri Pendayagunaan Aparatur Negara dan Reformasi Birokrasi Republik Indonesia Nomor 48 Tahun 2014 tentang Jabatan Fungsional Arsiparis; dan

9. Peraturan Kepala ANRI Nomor 6 Tahun 2016 Tentang Pedoman Sertifikasi Jabatan Fungsional Arsiparis.

\section{Pembahasan}

\section{Kedudukan, Tugas, dan}

\section{Wewenang Arsiparis}

Berdasarkan Peraturan Menteri Pendayagunaan Aparatur Negara dan Reformasi Birokrasi Republik Indonesia
Nomor 48 Tahun 2014 tentang Jabatan Fungsional Arsiparis, arsiparis mempunyai pekerjaan yang mandiri dan independen. Dengan predikat jabatan fungsional, arsiparis mempunyai kedudukan sebagai berikut:

a. Sebagai tenaga profesional di bidang kearsipan yang memiliki kemandirian dan independen dala m melaksanakan fungsi, tugas, dan kewenangannya pada $1 \mathrm{e} \mathrm{m} \mathrm{b}$ a g a $\mathrm{n}$ e a $\mathrm{r}$, pemerintahan daerah termasuk desa dan perguruan tinggi negeri.

b. Merupakan jabatan karier yang diduduki oleh Pegawai Negeri Sipil(PNS).

c. Dalam kedudukannya sebagai tenaga profesional, arsiparis memiliki fungsi, tugas, dan kewenangan di bidang kearsipan.

Adapun tugas dan fungsi arsiparis disebutkan pada PP No. 28 Tahun 2012 pasal 151 sebagai berikut: 
a. Menjaga terciptanya arsip dari kegiatan yang dilakukan oleh lembaga negara, pemda, lembaga pendidikan, perusahaan, orpol dan ormas;

b. Menjaga ketersediaan arsip yang autentik dan terpercaya sebagai alat bukti yang sah;

c. Menjaga terwujudnya pengelolaan arsip yang andal dan pemanfaatan arsip sesuai dengan ketentuan peraturan perundang-undangan;

d. Menjaga keamanan dan keselamatan arsip yang berfungsi untuk menjamin arsip-arsip yang berkaitan dengan hak-hak keperdataan rakyat melalui pengelolaan dan pemanfaatan arsip yang autentik dan terpercaya;

e. Menjaga keselamatan dan kelestarian arsip sebagai bukti pertanggungjawaban dalam kehidupan bermasyarakat, berbangsa, dan bernegara;

f. Menjaga keselamatan aset nasional dalam bidang ekonomi, sosial, politik, budaya, pertahanan, serta keamanan sebagai identitas dan jati diri bangsa; dan g. Menyediakan informasi guna meningkatkan kualitas pelayanan publik dalam pengelolaan dan pemanfaatan arsip yang autentik dan terpercaya.

Sebagai jabatan fungsional, arsiparis mempunyai kewenangan dalam bidang kearsipan sebagaimana diatur dalam PP 28 Tahun 2012 Pasal 152 sebagai berikut:

a. Menutup penggunaan arsip yang menjadi tanggung jawabnya oleh pengguna arsip apabila dipandang penggunaan arsip dapat merusak keamanan informasi dan/atau fisik arsip;

b. Menutup penggunaan arsip yang menjadi tanggung jawabnya oleh pengguna arsip yang tidak berhak sesuai dengan ketentuan peraturan perundang-undangan;

c. Melakukan penelusuran arsip pada pencipta arsip berdasarkan penugasan oleh pimpinan pencipta arsip atau kepala lembaga kearsipan sesuai dengan kewenangannya dalam rangka penyelamatan arsip. 
2. Pembagian Kategori Arsiparis

Sebagai jabatan karier, arsiparis mempunyai dua jenjang jabatan yaitu keterampilan dan keahlian. Pembagian jenjang jabatan arsiparis berdasarkan
PERMENPANRB 48 Tahun 2014 tentang Jabatan Fungsional Arsiparis dan PERMENPAN Nomor 3 Tahun 2009 tentang Jabatan Fungsional Arsiparis dan Angka Kreditnya adalah sebagai berikut:

Tabel 1

Jenjang Jabatan Arsiparis

\begin{tabular}{|c|c|l|l|}
\hline No. & Kategori & $\begin{array}{c}\text { PERMENPAN RB } \\
\text { No. 48 Tahun 2014 }\end{array}$ & $\begin{array}{c}\text { PERMENPAN } \\
\text { No. 3 Tahun 2009 }\end{array}$ \\
\hline 1 & Keterampilan & Arsiparis Pemula & Arsiparis Pelaksana \\
\hline & & Arsiparis Terampil & Arsiparis Pelaksana Lanjutan \\
\hline & & Arsiparis Mahir & Arsiparis Penyelia \\
\hline & & Arsiparis Penyelia & \\
\hline 2 & Keahlian & Arsiparis Ahli Pertama & Arsiparis Ahli Pertama \\
\hline & & Arsiparis Ahli Muda & Arsiparis Ahli Muda \\
\hline & & Arsiparis Ahli Madya & Arsiparis Ahli Madya \\
\hline & & Arsiparis Ahli Utama & Arsiparis Ahli Utama \\
\hline
\end{tabular}

Sumber: PERMENPANRB Nomor 48 Tahun 2014 dan PERMENPAN

Nomor 3 Tahun 2009.

Berdasarkan tabel di atas dapat diketahui bahwa ada perbedaan pada jenjang arsiparis keterampilan dimana pada PERMENPAN No. 3 Tahun 2009 hanya terdapat tiga level jabatan yaitu Arsiparis Pelaksana, Arsiparis Pelaksana Lanjutan dan Arsiparis Penyelia, sedangkan berdasarkan PERMENPAN RB Nomor 48 Tahun 2014 terdapat empat level jabatan yaitu Arsiparis Pemula, Arsiparis Terampil, Arsiparis Mahir dan Arsiparis Penyelia. Dengan demikian dapat dikatakan bahwa untuk 
dapat menduduki jabatan Arsiparis Penyelia membutuhkan waktu dan proses yang lebih lama karena terdapat empat level jabatan, yang sebelumnya hanya tiga level jabatan. Sedangkan untuk arsiparis ahli tidak ada perubahan masih tetap empat level, yaitu arsiparis ahli pertama, arsiparis ahli muda, arsiparis ahli madya dan arsiparis ahli utama.

\section{Arsiparis sebagai Tenaga}

\section{Profesional}

Arsiparis mempunyai kedudukan hukum sebagai tenaga profesional yang memiliki kemandirian dan i nde penden d a la m melaksanakan fungsi dan tugasnya. Hal ini sesuai dengan penjelasan Pasal 151 Ayat (1) PP No. 28 Tahun 2012.

Sebagai tenaga fungsional, arsiparis dituntut bekerja secara profesional. Tuntutan keprofesionalan arsiparis ini makin nyata dengan mulai diberlakukannya MEA di kawasan Asia Tenggara. Dengan adanya MEA peluang bagi SDM bidang kearsipan sangat terbuka, apalagi Negara Indonesia masih kekurangan arsiparis. Oleh karena itu, kebijakan dalam bidang kearsipan terkait dengan berlakunya MEA sangat diperlukan dan sudah mendesak agar kearsipan di Indonesia dapat maju dan berkembang, serta arsiparis Indonesia dapat terlindungi dan mampu bersaing dengan sumber daya kearsipan dari negara-negara anggota Asean.

Selain tuntutan MEA, peningkatan kemampuan arsiparis sebenarnya merupakan kebutuhan arsiparis itu sendiri, sebagai tenaga profesional yang dituntut mandiri dan independen. Hal ini sesuai dengan PP 28 Tahun 2012 Pasal 151 Ayat (1) yang menyebutkan bahwa arsiparis sebagai tenaga profesional harus memiliki sifat kemandirian dan independen. Adapun yang dimaksud dengan kemandirian maksudnya adalah 
bahwa dalam melaksanakan fungsi dan tugasnya arsiparis berpegang pada kompetensi yang dimilikinya, sedangkan independen maksudnya adalah bahwa arsiparis bebas dari pengaruh pihak manapun dalam melaksanakan kewenangannya berdasarkan pada kaidahkaidah kearsipan dan ketentuan peraturan perundang-undangan yang berlaku.

Agar dapat mandiri dan independen arsiparis dituntut mempunyai kompetensi dasar. Adapun kompetensi dasar yang harus dimiliki oleh seorang arsiparis adalah sebagai berikut:

1. Arsiparis berkewajiban untuk mengungkapkan informasi yang terolah dalam arsip

2. Arsiparis harus meramu dan mengolah informasi

3. Arsiparis harus mampu menyajikan informasi secara utuh, lengkap, akurat serta terpercaya kepada mereka yang tidak hanya memerlukan namun juga yang berhak

4. Arsiparis harus mengatur seberapa besar informasi dapat disajikan kepada siapa
5. Dalam sistem jaringan informasi kearsipan arsiparis berperan sebagai simpul

(Noerhadi Magetsari, 2011).

\section{Kebutuhan Jumlah Arsiparis Nasional}

Menurut Andi Kasman (2015) jumlah kebutuhan arsiparis nasional adalah 143.630 orang, jumlah arsiparis yang sudah ada (per 2015) sebanyak 3.241 orang atau baru 2,25\%. Dengan demikian saat ini Indonesia masih kekurangan arsiparis sebanyak 140.389 orang atau $97,75 \%$. Hal ini tentu saja menjadi peluang yang besar baik bagi aparatur sipil negara (ASN) maupun bagi para pencari kerja. Apabila ASN maupun para pencari kerja di Indonesia tidak dapat mengisi kekosongan/ kekurangan tersebut maka hal itu akan menjadi peluang bagi tenaga kerja dari kawasan Asia Tenggara. Oleh karena itu, pemerintah dalam hal ini ANRI harus terus berusaha menyiapkan dan melaksanakan kebijakan dalam rangka mempersiapkan arsiparis, calon 
arsiparis dan pengelola arsip agar mempunyai kompetensi yang baik dalam bidang kearsipan agar kekurangan jumlah arsiparis di Indonesia tetap diisi oleh warga Negara Indonesia sendiri. Oleh karena pentingnya arsip bagi negara, sebaiknya posisi arsiparis tetap diisi oleh warga Negara Indonesia sendiri agar informasi dan rahasia negara tidak bocor ke negara lain.

\section{Sertifikasi Arsiparis sebagai} Upaya Peningkatan Mutu Arsiparis

Sertifikasi kompetensi merupakan proses pemberian sertifikat kompetensi yang dilakukan secara sistematis dan obyektif melalui uji kompetensi yang mengacu kepada standar kompetensi kerja nasional Indonesia, standar internasional dan/atau standar khusus. Dalam rangka meningkatkan kompetensi arsiparis, ANRI telah melaksanakan kegiatan sertifikasi arsiparis.
Pelaksanaan sertifikasi arsiparis bersifat wajib dan sukarela. Bersifat wajib artinya pelaksanaan sertifikasi dilaksanakan berdasarkan program yang telah ditetapkan oleh ANRI (Direktorat SDM Kearsipan dan Sertifikasi), sedangkan yang bersifat sukarela berarti pelaksanaan sertifikasi atas inisiatif melalui permohonan dan pendanaan dari pemohon/peserta.

Adapun tujuan sertifikasi arsiparis menurut Peraturan ANRI Nomor 6 Tahun 2016 tentang Pedoman Sertifikasi Jabatan Fungsional Arsiparis adalah sebagai berikut:

a. M e n j a m i n m u t u penyelenggaraan kearsipan secara nasional;

b.Menjamin profesionalitas Arsiparis;

c. Memelihara, meningkatkan, dan melindungi kompetensi jabatan fungsional arsiparis;

d.Mengembangkan profesi Arsiparis; dan

e.Memberikan pengakuan formal terhadap kompetensi 
jabatan fungsional arsiparis.

\section{Sertifikasi kompetensi bidang} teknis arsiparis yang diselenggarakan oleh ANRI ada empat bidang, yaitu:

a. Sertifikasi pengelolaan arsip dinamis;

b. Sertifikasi pengelolaan arsip statis;

c. Sertifikasi pembinaan kearsipan; dan

d. Sertifikasi pengolahan dan penyajian arsip menjadi informasi.

Berikut adalah tabel yang menunjukkan kegiatan sertifikasi kearsipan yang telah dilakukan oleh ANRI sejak tahun 2009 hingga 2015:

Dari jumlah seluruh arsiparis

Tabel 2

Sertifikasi Arsiparis Tahun 2009 s.d. 2015

\begin{tabular}{|c|c|c|c|}
\hline Tahun & Bidang Kompetensi & Jumlah & Lulus \\
\hline \multirow[t]{2}{*}{2009} & 1. Pemberkasan Arsip & 23 Orang & 7 Orang \\
\hline & 2. Pengelolaan Dokumen Arsip Vital & 30 Orang & 6 Orang \\
\hline 2010 & 1. Pemberkasan Arsip & 31 Orang & 12 Orang \\
\hline \multirow[t]{2}{*}{2011} & 1. Tim Penilai Arsiparis & 29 Orang & 10 Orang \\
\hline & 2. Penyusunan JRA & 34 Orang & 17 Orang \\
\hline \multirow[t]{3}{*}{2012} & 1. Pemberkasan Arsip & 25 Orang & 22 Orang \\
\hline & 2. Penyusutan Arsip & 23 Orang & 16 Orang \\
\hline & 3. Manajemen Arsip Statis & 33 Orang & 30 Orang \\
\hline \multirow[t]{3}{*}{2013} & 1. Penyusunan JRA & 34 Orang & 32 Orang \\
\hline & 2. Manajemen Arsip Inaktif & 34 Orang & 32 Orang \\
\hline & 3. Pengelolaan Arsip Statis & 34 Orang & 32 Orang \\
\hline \multirow[t]{8}{*}{2014} & 1. Pengelolaan Arsip Dinamis & 56 Orang & 39 Orang \\
\hline & 2. Pengelolaan Arsip Dinamis & 23 Orang & 20 Orang \\
\hline & 3. Pengelolaan Arsip Dinamis & 38 Orang & 22 Orang \\
\hline & 4. Pengelolaan Arsip Dinamis & 65 Orang & 32 Orang \\
\hline & 5. Pengelolaan Arsip Dinamis & 66 Orang & 32 Orang \\
\hline & 6. Pengelolaan Arsip Dinamis & 81 Orang & 38 Orang \\
\hline & 7. Pengelolaan Arsip Dinamis PT. PJB & 41 Orang & 24 Orang \\
\hline & 8. Pengelolaan Arsip Dinamis Pemda Jabar & 51 Orang & 40 Orang \\
\hline \multirow[t]{3}{*}{2015} & $\begin{array}{l}\text { 1. Pengelolaan Arsip Dinamis PT. Semen } \\
\text { Padang }\end{array}$ & 31 Orang & 23 Orang \\
\hline & 2. Pengelolaan Arsip Dinamis Pemda Jatim & 22 Orang & 32 Orang \\
\hline & Jumlah & 804 Orang & 509 Orang \\
\hline
\end{tabular}

Sumber: Abdullah Shobri, 2015 dalam Sertifikasi Arsiparis sebagai Implementasi Peraturan Menteri Pendayagunaan Aparatur Negara dan Reformasi Birokrasi Nomor 48 Tahun 2014 tentang Jabatan Fungsional Arsiparis. 
yang ada di Indonesia saat ini sebanyak 3.241 orang, jumlah arsiparis yang tersertifikasi baru 24,8\%. Oleh karena itu, ANRI diharapkan menambah kuota dan frekuensi sertifikasi untuk setiap jenis sertifikasi agar semua arsiparis dapat tersertifikasi sesuai dengan bidang pekerjaan arsiparis .

Sedangkan untuk sertifikasi jabatan fungsional arsiparis diatur tersendiri dalam Peraturan Kepala ANRI Nomor 6 Tahun 2016 tentang Pedoman Sertifikasi Jabatan Fungsional Arsiparis. Sertifikasi Jabatan Fungsional Arsiparis dilaksanakan dalam rangka:

a. Penyesuaian ke dalam jabatan fungsional arsiparis (inpassing);

b. Kenaikan jenjang jabatan setingkat lebih tinggi;

c. Alih jabatan dari kategori keterampilan ke kategori keahlian;

d. Pengangkatan kembali bagi PNS ke dalam jabatan fungsional arsiparis kategori keterampilan; e. Pengangkatan kembali bagi PNS ke dalam jabatan fungsional arsiparis kategori keahlian;

f. Perpindahan jabatan dari jabatan struktural ke dalam jabatan fungsional arsiparis; dan

g. Perpindahan jabatan dari pejabat fungsional tertentu lainnya ke dalam jabatan fungsional arsiparis kategori keterampilan dan kategori keahlian.

Hasil kelulusan uji kompetensi kearsipan tersebut menjadi syarat untuk:

a. Pengangkatan dalam jabatan fungsional arsiparis melalui jalur inpassing;

b. Kenaikan jabatan fungsional arsiparis setingkat lebih tinggi;

c. Alih jabatan dari arsiparis kategori keterampilan ke arsiparis kategori keahlian;

d. Pengangkatan kembali ke dalam jabatan fungsional arsiparis kategori 
keterampilan dan/atau arsiparis kategori keahlian;

e. Alih jabatan bagi pejabat struktural yang akan diangkat dalam jabatan fungsional arsiparis; dan

f. Alih jabatan dari jabatan fungsional tertentu lainnya ke dalam jabatan fungsional arsiparis kategori keterampilan dan/atau arsiparis kategori keahlian.

Sertifikasi jabatan fungsional arsiparis berdasarkan Peraturan Kepala ANRI Nomor 6 Tahun 2016 tersebut sudah mulai dilaksanakan pada tahun 2016 ini. Hal ini sesuai dengan surat dari Deputi Pembinaan Kearsipan ANRI tanggal 24 Maret 2016. Salah satu syaratnya adalah "telah menduduki jabatan terakhir minimal 2 (dua) tahun". Hal ini mengakibatkan arsiparis tidak bisa naik jabatan setiap tahun. Dengan kata lain setelah menduduki jabatan terakhir minimal dua tahun seorang arsiparis baru bisa mendaftarkan diri sebagai peserta sertifikasi jabatan arsiparis untuk naik jabatan setingkat lebih tinggi. Dengan jumlah kuota sertifikasi jabatan yang terbatas tentu tidak se mua arsiparis yang mendaftarkan diri bisa mengikuti sertifikasi jabatan pada tahun yang sama dengan pendaftarannya. Hal ini tentu akan menimbulkan antrian panjang bagi arsiparis. Serajin apapun arsiparis bekerja, termasuk rajin membuat Daftar Usulan Penetapan Angka Kredit (DUPAK), karena sudah terbentur persyaratan akan menimbulkan kerugian bagi arsiparis. Dengan demikian rumus $2: 1$ bagi fungsional arsiparis (dua tahun naik pangkat dan satu tahun naik jabatan) tidak berlaku lagi. Hal ini bisa berakibat menurunkan minat pegawai untuk menjadi arsiparis.

\section{E. Penutup}

\section{Kesimpulan}

Berdasarkan uraian tersebut di atas dapat disimpulkan bahwa:

a. Sertifikasi kearsipan bagi arsiparis merupakan tuntutan apabila dikaitkan dengan perkembangan bangsa dan negara 
khususnya dengan berlakunya MEA 2015 agar posisi arsiparis tidak digeser oleh SDM kearsipan dari negara-negara tetangga sesama anggota Asean.

b. Sertifikasi kompetensi arsiparis menjadi kebutuhan bagi arsiparis itu sendiri apabila dikaitkan dengan persyaratan kenaikan jabatan arsiparis yang harus lulus sertifikasi untuk kenaikan Jabatan Fungsional Arsiparis setingkat lebih tinggi.

c. Persyaratan sertifikasi jabatan bagi arsiparis perlu dikaji ulang agar tidak menimbulkan kerugian bagi arsiparis.

\section{Saran}

Melalui tulisan ini, penulis memberikan masukan sebagai berikut:

a. Terkait dengan MEA, sebaiknya posisi arsiparis tetap diisi oleh warga Negara Indonesia sendiri agar informasi dan rahasia negara tidak bocor ke negara lain;

b. ANRI dan lembaga/instansi pemerintah yang terkait diharapkan menciptakan pembinaan arsiparis/tenaga kearsipan yang profesional dan andal melalui diklat yang berkualitas;

c. Pengembangan kemampuan arsiparis melalui sertifikasi sesuai kompetensi kearsipan masih perlu ditingkatkan sehingga jumlah pada masing-masing jenis sertifikasi perlu ditambah $\mathrm{s}$ e h i n g g a $\mathrm{t} \mathrm{i} \mathrm{d} \mathrm{a} \mathrm{k}$ menimbulkan antrian yang terlalu lama bagi arsiparis di Indonesia; dan

d. Pusdiklat Kearsipan ANRI perlu meningkatkan kualitas $\mathrm{d}$ a $\mathrm{n} \quad \mathrm{k} \mathrm{u}$ a n t i t a $\mathrm{s}$ penyelenggaraan diklat sehingga dapat membantu pemerintah dala m $\mathrm{m}$ e $\mathrm{n} \mathrm{c}$ i $\mathrm{p} \mathrm{t}$ a $\mathrm{k}$ a $\mathrm{n}$ arsiparis/sumber daya manusia kearsipan yang profesional dan mandiri. 


\section{DAFTAR PUSTAKA}

\section{Undang-Undang dan Peraturan:}

Undang-Undang No. 43 Tahun 2009 tentang Kearsipan.

Peraturan Pemerintah No. 28 Th 2012 tentang Pelaksanaan UndangUndang No.43 Tahun 2009 tentang Kearsipan.

Peraturan Menteri Pendayagunaan Aparatur Negara dan Reformasi Birokrasi Nomor 48 Tahun 2014 tentang Jabatan Fungsional Arsiparis.

Peraturan Kepala Arsip Nasional Republik Indonesia Nomor 11 Tahun 2009 tentang Pedoman Umum Akreditasi dan Sertifikasi Kearsipan.

Peraturan Kepala Arsip Nasional Republik Indonesia Nomor 25 Tahun 2011 tentang Pedoman Sertifikasi Sumber Daya Manusia Kearsipan bagi Pejabat Fungsional Arsiparis Pegawai Negeri Sipil.

Peraturan Kepala Arsip Nasional Republik Indonesia Nomor 6 Tahun 2016 Tentang Pedoman Sertifikasi Jabatan Fungsional Arsiparis.

\section{Makalah:}

Andi Kasman, 2015. "Kebijakan $\mathrm{P}$ e $\mathrm{mb}$ i $\mathrm{n}$ a $\mathrm{n}$ d a $\mathrm{n}$
Pengembangan S D M Kearsipan Pasca Peraturan Menteri PAN Dan RB Nomor 48 Tahun 2012 Tentang JFA", makalah pada Workshop Sertifikasi Arsiparis yang dilaksanakan oleh Direktorak SDMK dan Sertifikasi ANRI, Jakarta-ANRI.

Abdullah Shobri, 2015. "Sertifikasi Arsiparis Arsiparis Sebagai Implementasi Peraturan Menteri Pendayagunaan Aparatur Negara dan Reformasi Birokrasi Nomor 48 Tahun 2014 tentang Jabatan Fungsional Arsiparis." Makalah pada Workshop Sertifikasi Arsiparis yang dilaksanakan oleh Direktorak SDMK dan Sertifikasi ANRI, JakartaANRI.

\section{Internet:}

Masyarakat Ekonomi ASEAN ( MEA ), https://id. wikipedia.org/wiki/Masyarak at_Ekonomi_ASEAN diakses tanggal 24 Februari 2016.

Komite Akreditasi Nasional, Apa perbedaan "akreditasi" dengan "sertifikasi"?, http://www.kan.or.id/?page_i $\mathrm{d}=70$ \&lang=id, diakses tanggal 3 Juni 2016. 
Masyarakat Ekonomi ASEAN (MEA) dan Perekonomian Indonesia, G.T. Suroso, 2015 http://www.bppk.kemenkeu.g o.id/publikasi/artikel/150a r t i k e 1 - k e u a n g a n umum/20545-masyarakatekonom-asean-mea-danperekonomian-indonesia, diakses tanggal 24 Februari 2016). 